\title{
KEMAMPUAN INSTRUMEN PENILAIAN KINERJA PUSKESMAS DALAM MENGAKOMODASI IMPLEMENTASI FUNGSI PUSKESMAS
}

\section{The Ability of Public Health Center Performance Appraisal Instrument Accommodating the Implementation of Public Health Center Functions}

\author{
Nuzulul Kusuma Putri ${ }^{1}$, Ernawaty ${ }^{1}$, Thinni Nurul R ${ }^{1}$, Hario Megatsari ${ }^{2}$ \\ ${ }^{1}$ Departemen Administrasi dan Kebijakan Kesehatan, Fakultas Kesehatan Masyarakat, \\ Universitas Airlangga, \\ ${ }^{2}$ Departemen Promosi Kesehatan dan Ilmu Perilaku, Fakultas Kesehatan Masyarakat, \\ Universitas Airlangga \\ (nuzululkusuma@fkm.unair.ac.id)
}

\begin{abstract}
ABSTRAK
Setelah pemberlakukan Jaminan Kesehatan Nasional, puskesmas dianggap semakin berat menjalankan fungsi kuratif daripada preventif. Implementasi fungsi puskesmas sudah seharusnya dapat dikendalikan melalui sebuah instrumen Penilaian Kinerja Puskesmas (PKP) yang mampu mengakomodasi fungsi puskesmas secara seimbang. Penelitian ini menganalisis kemampuan instrumen Penilaian Kinerja Puskesmas dalam mengakomodasi implementasi fungsi puskesmas. Implementasi fungsi puskesmas dianalisis melalui studi dokumen kebijakan yang mengatur fungsi puskesmas. Nominal Group Technique (NGT) dengan kepala puskesmas di Kota Surabaya dilakukan untuk menyimpulkan akomodasi setiap fungsi puskesmas pada setiap komponen penilaian yang digunakan dalam instrumen PKP. Ada tiga aspek yang dinilai dalam PKP, yakni aspek pelayanan kesehatan (wajib dan pengembangan), pelaksanaan manajemen puskesmas, dan mutu pelayanan kesehatan. PKP untuk program wajib dan pengembangan puskesmas lebih menilai fungsi puskesmas sebagai pelayanan kesehatan masyarakat. Komponen penilaian untuk mutu pelayanan kesehatan dan kegiatan manajemen puskesmas justru lebih banyak menilai mutu fungsi pelayanan kesehatan perorangan. Fungsi puskesmas sebagai pusat penggerak pembangunan berwawasan kesehatan merupakan fungsi yang paling jarang dinilai sebagai kinerja puskesmas. Penelitian ini menunjukkan bahwa instrumen PKP yang selama ini digunakan belum mampu mengakomodasi implementasi fungsi puskesmas secara seimbang.
\end{abstract}

Kata kunci : Fungsi puskesmas, penilaian kinerja puskesmas, implementasi

\section{ABSTRACT}

After National Health Insurance launched, Public Health Center is criticized too abandoned by curative function rather than its preventive functions. The functions of Public Health Center should be controlled to be implemented equally through a proper Performance Assessment of Public Health Centres (PKP) instrument. This study aims to analyze the ability of PKP instruments accommodating the implementation of PHC functions. Implementation of the PHC functions analyzed through policy analysis regulating PHC functions. Nominal Group Technique (NGT) is conducted to draw conclusions of the accommodation of each function in PKP. There are three aspects assessed in the PKP instrument i.e. Compulsory and development health programs, management, and service quality. The study showed that the PKP instruments mostly focused on assessing the PHC functions as a public health service. Components for health care quality assessment and management activities in PKP instrument tend to assess more on the quality of personal health services function. Public Health Center function as motor in health oriented development is the least function that assessed in PKP. This study shows that the PKP instruments have not been able to accommodate the implementation of PHC function in a balanced manner.

Keywords : Functions of PHC, PHC Performance Assessment, implementation 


\section{PENDAHULUAN}

Puskesmas merupakan institusi kesehatan yang berperan penting dalam dunia kesehatan Indonesia. Pada berbagai dokumen kebijakan yang mengatur kebijakan dasar puskesmas, puskesmas dituntut tidak hanya memberikan pelayanan kesehatan, tetapi juga menggerakkan pembangunan yang sekaligus sebagai wadah untuk memberdayakan masyarakat. Fungsi puskesmas selanjutnya dimanifestasikan melalui berbagai jenis kegiatan yang dilakukan puskesmas. Hal ini menyebabkan jenis kegiatan puskesmas beragam tidak hanya melayani pengobatan saja sehingga beban kerja puskesmas sangat tinggi.

Tingginya beban kerja puskesmas menyebabkan pelaksanaan fungsi puskesmas yang tercantum dalam Keputusan Menteri Kesehatan Republik Indonesia Nomor 128/Menkes/SK/II/2004 dirasa kurang berjalan maksimal. ${ }^{1}$ Masyarakat lebih mengenal puskesmas sebagai pemberi pelayanan kuratif saja. Survei awal yang dilakukan oleh peneliti pada Juni 2015, menunjukkan bahwa mayoritas masyarakat masih berpendapat puskesmas adalah tempat berobat sedangkan unsur preventif dan promotif tidak nampak sama sekali. Kesibukan puskesmas dalam memberikan pelayanan kuratif diperparah dengan sistem pertanggungjawaban kegiatan puskesmas yang membutuhkan waktu yang sangat menyita. Ketenagaan puskesmas yang terbatas semakin menyebabkan upaya preventif dan promotif menjadi prioritas yang kesekian. Fungsi yang tercantum dalam KMK 128/Menkes/SK/II/2004 ini kemudian diatur ulang melalui Peraturan Menteri Kesehatan Nomor 75 Tahun 2014 Tentang Pusat Kesehatan Masyarakat. PMK Nomor 75 Tahun 2014 ini diterbitkan setelah pelaksanaan Jaminan Kesehatan Nasional.

Pada era Jaminan Kesehatan Nasional, puskesmas merupakan Fasilitas Kesehatan Tingkat Pertama (FKTP) yang dibayar dengan sistem kapitasi oleh Badan Penyelenggara Jaminan Sosial (BPJS) Kesehatan. Oleh karena itu, agar dapat sukses menjalankan pelayanan kesehatan di era Jaminan Kesehatan Nasional, puskesmas harus sadar bahwa upaya preventif dan promotif merupakan modal penting. ${ }^{2}$ Berbeda dengan FKTP lainnya yang hanya memberikan upaya preventif dan promotif untuk individu, puskesmas juga memiliki kewajiban untuk melakukan upaya preventif dan promotif dengan sasaran komunitas.

Puskesmas sendiri merupakan Unit Pelaksana Teknis Dinas Kesehatan Kabupaten/Kota yang setiap kinerjanya akan membangun kinerja Dinas Kesehatan Kabupaten/Kota. Untuk mengevaluasi kinerja puskesmas, Dinas Kesehatan Kota/Kabupaten menggunakan instrumen Penilaian Kinerja Puskesmas (PKP). Instrumen PKP disusun oleh Dinas Kesehatan Provinsi sehingga seragam digunakan untuk satu provinsi. Instrumen ini memuat berbagai jenis kegiatan puskesmas yang harus dilakukan agar dapat dinilai kinerjanya. Tujuan dari sebuah sistem penilaian kinerja adalah untuk mengukur dan menilai secara kuantitatif pencapaian tujuan dan tugas organisasi. Hasil penilaian kinerja organisasi pada sektor publik selain akan mampu menunjukkan kinerja organisasi dapat juga menunjukkan kesesuaian penggunaan dana. ${ }^{3}$

Berdasarkan kondisi tersebut, penelitian bertujuan untuk menganalisis kemampuan instrumen Penilaian Kinerja Puskesmas dalam mengakomodasi implementasi fungsi puskesmas. Penelitian ini diharapkan dapat menunjukkan apakah instrumen Penilaian Kinerja Puskesmas telah mampu mengukur implementasi fungsi puskesmas secara seimbang sehingga puskesmas tidak hanya dikenal sebagai pemberi pelayanan pengobatan saja. Hasil penelitian diharapkan dapat menjadi pertimbangan Dinas Kesehatan untuk melakukan kajian ulang tentang cara menyeimbangkan aktivitas puskesmas agar dapat mengimplementasikan fungsinya dengan seimbang.

\section{BAHAN DAN METODE}

Penelitian ini merupakan penelitian deskriptif observasional. Pengumpulan data dilakukan melalui studi dokumen kebijakan dan Nominal Group Technique (NGT). Kebijakan yang ditelaah adalah kebijakan yang mengatur fungsi puskesmas dan instrumen Penilaian Kinerja Puskesmas yang dikeluarkan oleh Dinas Kesehatan Provinsi Jawa Timur tahun 2012. Instrumen PKP edisi 2012 ini merupakan instrumen terbaru yang digunakan oleh Dinas Kesehatan Kota Surabaya untuk menilai kinerja puskesmas Kota Surabaya. Telaah terhadap akomodasi fungsi puskesmas dalam instrumen PKP dilakukan dengan melakukan Nominal Group Technique (NGT). Telaah dilakukan secara kua- 
litatif melalui NGT dengan 9 orang kepala puskesmas di Kota Surabaya sebagai peserta NGT. Hasil NGT digunakan untuk menentukan fungsi puskesmas yang paling dominan dalam setiap jenis kegiatan yang dinilai dalam instrumen PKP. Setiap peserta NGT diminta untuk menilai fungsi yang terukur dalam setiap jenis kegiatan yang ada dalam instrumen PKP. Fungsi puskesmas yang dominan didasarkan pada frekuensi jawaban terbanyak yang diberikan oleh peserta NGT.

\section{HASIL}

Fungsi puskesmas selama lebih dari 10 tahun diatur melalui Keputusan Menteri Kesehatan Republik Indonesia Nomor 128/Menkes/SK/ II/2004 tentang Kebijakan Dasar Pusat Kesehatan Masyarakat. Peraturan ini baru dicabut dan diperbarui pada tahun 2014 melalui Peraturan Menteri Kesehatan Nomor 75 tahun 2014 tentang Pusat Kesehatan Masyarakat. Permenkes 75 Tahun 2014 merupakan peraturan terbaru tentang puskesmas yang diterbitkan.

Dengan berlakukanya Permenkes Nomor 75 tahun 2014, fungsi puskesmas tidak berubah, tetapi bertambah. Puskesmas tidak hanya menjadi penyedia pelayanan kesehatan masyarakat dan individu, tetapi puskesmas juga berfungsi sebagai tempat belajar tenaga kesehatan. Pada penjelasan mengenai fungsi wahana pendidikan belum ada ketentuan mengenai jenis kegiatan yang seharusnya dilakukan oleh puskesmas untuk dapat menjalankan fungsi ini. Fungsi puskesmas sebagai wahana pendidikan merupakan fungsi baru yang belum diatur dalam Keputusan Menteri Kesehatan Republik Indonesia Nomor 128/Menkes/SK/ II/2004 sebelumnya. Adanya tambahan fungsi berkonsekuensi pada adanya ukuran kinerja yang mengatur tercapainya fungsi tersebut.

Selama ini untuk menilai kinerja puskesmas digunakan instrumen Penilaian Kinerja Puskesmas (PKP). PKP merupakan satu-satunya instrumen kinerja yang digunakan oleh Dinas Kesehatan Kabupaten/Kota untuk menilai kinerja puskesmas. Fungsi pengawasan yang ada dalam PKP diharapkan dapat dijadikan sebagai bahan pembinaan terhadap implementasi fungsi puskesmas. Ada tiga ruang lingkup kegiatan puskesmas yang dinilai dalam PKP yakni penilaian terhadap pencapaian pelayanan kesehatan, manajemen puskesmas dan mutu pelayanan puskesmas. Konsekuensinya adalah semua kegiatan yang dilakukan oleh Puskesmas harus diarahkan untuk pencapaian ukuran kinerja tersebut. Kegiatan lain yang dilakukan oleh puskesmas selain ketiga jenis kegiatan tersebut tidak dianggap sebagai kinerja puskesmas.

Pada komponen pencapaian pelayanan kesehatan yang dinilai adalah program wajib dan pengembangan yang dilakukan oleh puskesmas. Untuk program wajib puskesmas setidaknya ada 30 jenis kegiatan puskesmas yang dipakai sebagai indikator penilaian. Semua jenis kegiatan ini merupakan kegiatan yang harus dilakukan oleh puskesmas. Sedangkan pada program pengembangan atau inovatif puskesmas ada 13 jenis kegiatan yang dapat dilakukan oleh puskesmas. Khusus untuk program pengembangan ini, setiap Dinas Kesehatan Kota/Kabupaten dapat menyesuaikan dengan program pengembangan yang dilakukan di Kota/ Kabupatennya. Selain menilai kinerja pencapaian pelayanan, instrumen PKP juga menilai mengenai mutu pelayanan puskesmas. Namun, terlihat ketidaksesuaian pada kedua ruang lingkup penilaian tersebut. Pelayanan yang dilakukan puskesmas baik wajib maupun pengembangan hanya dinilai mutu pelayanannya melalui 11 indikator mutu saja, sedangkan jenis kegiatan yang dinilai dalam ruang lingkup manajemen puskesmas mencakup 6 jenis kegiatan manajemen yang dilakukan oleh puskesmas sehari-hari.

Selanjutnya pada penelitian ini, fungsi puskesmas yang dianalisis adalah fungsi puskesmas yang diatur dalam Keputusan Menteri Kesehatan Republik Indonesia Nomor 128/Menkes/ SK/II/2004 tentang Kebijakan Dasar Pusat Kesehatan Masyarakat. Kebijakan ini dijadikan dasar analisis karena hingga tahun 2016, instrumen PKP yang digunakan di Provinsi Jawa Timur adalah PKP edisi 2012. Maka perbandingan yang sesuai adalah membandingkan PKP edisi 2012 dengan fungsi puskesmas pada Kepmenkes Nomor 128/ Menkes/SK/II/2004. Tabel 1 menunjukkan hasil NGT yang dilakukan dengan Kepala Puskesmas di Kota Surabaya mengenai akomodasi fungsi puskesmas dalam instrumen PKP.

Program kesehatan wajib puskesmas telah diatur melalui Kepmenkes Nomor 128/Menkes/ SK/II/2004. Kegiatan ini wajib dilakukan oleh semua puskesmas yang ada di Indonesia. Pada 
Tabel 1. Akomodasi Fungsi Puskesmas dalam Komponen Penilaian Kinerja Puskesmas untuk Program Wajib Puskesmas

\begin{tabular}{|c|c|c|c|c|c|c|c|c|c|c|c|c|}
\hline \multirow{3}{*}{ No. } & \multirow{3}{*}{ Jenis Kegiatan } & \multicolumn{8}{|c|}{ Fungsi } & \multirow{2}{*}{\multicolumn{2}{|c|}{ Total }} & \multirow{3}{*}{$\begin{array}{c}\text { Fungsi } \\
\text { yang } \\
\text { dominan }\end{array}$} \\
\hline & & \multicolumn{2}{|c|}{1} & \multicolumn{2}{|c|}{2} & \multicolumn{2}{|c|}{$3 a$} & \multicolumn{2}{|c|}{$3 b$} & & & \\
\hline & & $\mathbf{n}$ & $\%$ & $\mathbf{n}$ & $\%$ & $\mathbf{n}$ & $\%$ & $\mathbf{n}$ & $\%$ & $\mathbf{n}$ & $\%$ & \\
\hline & Promosi Kesehatan & & & & & & & & & & & \\
\hline 1 & Pengembangan desa siaga & 2 & 20,0 & 5 & 60,0 & 0 & 0,0 & 2 & 20,0 & 9 & 100 & 2 \\
\hline 2 & $\begin{array}{l}\text { Pemberdayaan masyarakat } \\
\text { dalam PHBS }\end{array}$ & 2 & 20,0 & 5 & 60,0 & 0 & 0,0 & 2 & 20,0 & 9 & 100 & 2 \\
\hline 3 & $\begin{array}{l}\text { Pengembangan upaya } \\
\text { kesehatan bersumberdaya } \\
\text { masyarakat (UKBM) }\end{array}$ & 0 & 0,0 & 7 & 75,0 & 0 & 0,0 & 2 & 25,0 & 9 & 100 & 2 \\
\hline 4 & $\begin{array}{l}\text { Penyuluhan NAPZA } \\
\text { Kesehatan Lingkungan }\end{array}$ & 2 & 20,0 & 2 & 20,0 & 0 & 0,0 & 5 & 60,0 & 9 & 100 & $3 b$ \\
\hline 5 & Penyehatan air & 4 & 42,9 & 3 & 35,7 & 0 & 0,0 & 2 & 21,4 & 9 & 100 & 1 \\
\hline 6 & $\begin{array}{l}\text { Penyehatan makanan dan } \\
\text { minuman }\end{array}$ & 5 & 55,6 & 3 & 33,3 & 0 & 0,0 & 1 & 11,1 & 9 & 100 & 1 \\
\hline 7 & $\begin{array}{l}\text { Penyehatan perumahan dan } \\
\text { sanitasi dasar }\end{array}$ & 4 & 47,1 & 4 & 41,2 & 0 & 0,0 & 1 & 11,8 & 9 & 100 & 1 \\
\hline 8 & $\begin{array}{l}\text { Pembinaan tempat-tempat } \\
\text { umum }\end{array}$ & 6 & 62,5 & 2 & 25,0 & 0 & 0,0 & 1 & 12,5 & 9 & 100 & 1 \\
\hline 9 & Klinik sanitasi & 2 & 20,0 & 2 & 20,0 & 0 & 0,0 & 5 & 60,0 & 9 & 100 & $3 b$ \\
\hline 10 & $\begin{array}{l}\text { STBM } \\
\text { Upava Perbaikan Gizi }\end{array}$ & 2 & 22,9 & 5 & 51,4 & 0 & 0,0 & 2 & 25,7 & 9 & 100 & 2 \\
\hline 11 & Pelayanan gizi masyarakat & 0 & 0,0 & 0 & 0,0 & 2 & 22,2 & 7 & 77,8 & 9 & 100 & $3 b$ \\
\hline 12 & Penanganan gangguan gizi & 0 & 0,0 & 0 & 0,0 & 2 & 22,2 & 7 & 77,8 & 9 & 100 & $3 b$ \\
\hline 13 & $\begin{array}{l}\text { Pemanfaatan status gizi } \\
\text { KIA termasuk KB }\end{array}$ & 0 & 0,0 & 2 & 22,2 & 1 & 11,1 & 6 & 66,7 & 9 & 100 & $3 b$ \\
\hline 14 & Kesehatan ibu & 0 & 0,0 & 0 & 0,0 & 6 & 66,7 & 3 & 33,3 & 9 & 100 & $3 a$ \\
\hline 15 & Kesehatan bayi & 0 & 0,0 & 0 & 0,0 & 6 & 66,7 & 3 & 33,3 & 9 & 100 & $3 a$ \\
\hline 16 & $\begin{array}{l}\text { Upaya kesehatan balita dan } \\
\text { anak pra sekolah }\end{array}$ & 0 & 0,0 & 1 & 11,1 & 4 & 44,4 & 4 & 44,4 & 9 & 100 & 3 \\
\hline 17 & $\begin{array}{l}\text { Upaya kesehatan anak usia } \\
\text { sekolah dan remaja }\end{array}$ & 0 & 0,0 & 3 & 33,3 & 0 & 0,0 & 6 & 66,7 & 9 & 100 & $3 b$ \\
\hline 18 & $\begin{array}{l}\text { Pelayanan keluarga berencana } \\
\text { Upaya P3M }\end{array}$ & 0 & 0,0 & 0 & 0,0 & 2 & 22,2 & 7 & 77,8 & 9 & 100 & $3 b$ \\
\hline 19 & Diare & 1 & 15,4 & 1 & 7,7 & 4 & 46,2 & 3 & 30,8 & 9 & 100 & $3 a$ \\
\hline 20 & ISPA & 1 & 14,3 & 0 & 0,0 & 5 & 57,1 & 3 & 28,6 & 9 & 100 & $3 a$ \\
\hline 21 & Kusta & 1 & 14,3 & 0 & 0,0 & 5 & 57,1 & 3 & 28,6 & 9 & 100 & $3 a$ \\
\hline 22 & TB Paru & 1 & 14,3 & 0 & 0,0 & 5 & 57,1 & 3 & 28,6 & 9 & 100 & $3 a$ \\
\hline 23 & $\begin{array}{l}\text { Pencegahan dan } \\
\text { penanggulangan PMS dan } \\
\text { HIV/AIDS }\end{array}$ & 3 & 28,6 & 1 & 14,3 & 1 & 14,3 & 4 & 42,9 & 9 & 100 & $3 b$ \\
\hline 24 & Demam Berdarah (DBD) & 2 & 22,6 & 1 & 9,7 & 2 & 19,4 & 4 & 48,4 & 9 & 100 & $3 b$ \\
\hline 25 & Malaria & 2 & 21,4 & 0 & 0,0 & 7 & 78,6 & 0 & 0,0 & 9 & 100 & $3 a$ \\
\hline 26 & $\begin{array}{l}\text { Pencegahan dan } \\
\text { penanggulangan rabies }\end{array}$ & 2 & 18,2 & 0 & 0,0 & 4 & 45,5 & 3 & 36,4 & 9 & 100 & $3 a$ \\
\hline 27 & Pelayanan imunisasi & 2 & 17,4 & 0 & 2,3 & 2 & 23,3 & 5 & 57,0 & 9 & 100 & $3 b$ \\
\hline 28 & $\begin{array}{l}\text { Pengamatan penyakit } \\
\text { (surveilans epidemiologi) } \\
\text { Pengobatan }\end{array}$ & 2 & 25,0 & 0 & 0,0 & 0 & 0,0 & 7 & 75,0 & 9 & 100 & $3 b$ \\
\hline 29 & Pengobatan & 0 & 0,0 & 0 & 0,0 & 9 & 100,0 & 0 & 0,0 & 9 & 100 & $3 a$ \\
\hline 30 & Pemeriksaan laboratorium & 0 & 0,0 & 0 & 0,0 & 8 & 92,6 & 1 & 7,4 & 9 & 100 & $3 a$ \\
\hline
\end{tabular}

\section{Keterangan:}

1. Pusat penggerak pembangunan berwawasan kesehatan

2. Pusat pemberdayaan masyarakat

3. Pusat pelayanan kesehatan strata pertama : 3a. Pelayanan kesehatan perorangan; 3b. Pelayanan kesehatan masyarakat 
Tabel 2. Akomodasi Fungsi Puskesmas dalam Komponen Penilaian Kinerja Puskesmas untuk Program Pengembangan Puskesmas

\begin{tabular}{|c|c|c|c|c|c|c|c|c|c|c|c|c|}
\hline \multirow{3}{*}{ No. } & \multirow{3}{*}{ Jenis Kegiatan } & \multicolumn{8}{|c|}{ Fungsi } & \multirow{2}{*}{\multicolumn{2}{|c|}{ Total }} & \multirow{3}{*}{$\begin{array}{c}\text { Fungsi } \\
\text { yang } \\
\text { dominan }\end{array}$} \\
\hline & & \multicolumn{2}{|c|}{1} & \multicolumn{2}{|c|}{2} & \multicolumn{2}{|c|}{$3 \mathbf{a}$} & \multicolumn{2}{|c|}{$\mathbf{3 b}$} & & & \\
\hline & & $\mathbf{n}$ & $\%$ & $n$ & $\%$ & $\mathbf{n}$ & $\%$ & n & $\%$ & $\mathbf{n}$ & $\%$ & \\
\hline 1 & Puskesmas dengan rawat inap & 0 & 0,0 & 0 & 0,0 & 8 & 88,9 & 1 & 11,1 & 9 & 100 & $3 a$ \\
\hline 2 & Upaya kesehatan usia lanjut & 1 & 11,1 & 2 & 22,2 & 1 & 11,1 & 5 & 55,6 & 9 & 100 & $3 \mathrm{~b}$ \\
\hline 3 & $\begin{array}{l}\text { Upaya kesehatan mata/ } \\
\text { pencegahan kebutaan }\end{array}$ & 0 & 0,0 & 0 & 0,0 & 4 & 44,4 & 5 & 55,6 & 9 & 100 & $3 b$ \\
\hline 4 & $\begin{array}{l}\text { Upaya kesehatan telinga/ } \\
\text { pencegahan gangguan } \\
\text { pendengaran }\end{array}$ & 0 & 0,0 & 0 & 0,0 & 4 & 44,4 & 5 & 55,6 & 9 & 100 & $3 \mathrm{~b}$ \\
\hline 5 & Upaya kesehatan jiwa & 0 & 0,0 & 1 & 11,1 & 3 & 33,3 & 5 & 55,6 & 9 & 100 & $3 b$ \\
\hline 6 & Upaya kesehatan olah raga & 1 & 11,1 & 4 & 44,4 & 0 & 0,0 & 4 & 44,4 & 9 & 100 & $2,3 b$ \\
\hline 7 & $\begin{array}{l}\text { Pencegahan dan } \\
\text { penanggulangan penyakit gigi }\end{array}$ & 0 & 0,0 & 1 & 11,1 & 3 & 33,3 & 5 & 55,6 & 9 & 100 & $3 b$ \\
\hline 8 & $\begin{array}{l}\text { Perawatan kesehatan } \\
\text { masyarakat }\end{array}$ & 0 & 0,0 & 1 & 11,1 & 1 & 11,1 & 7 & 77,8 & 9 & 100 & $3 b$ \\
\hline 9 & Bina kesehatan tradisional & 0 & 0,0 & 4 & 44,4 & 0 & 0,0 & 5 & 55,6 & 9 & 100 & $3 b$ \\
\hline 10 & Bina kesehatan kerja & 0 & 0,0 & 2 & 22,2 & 2 & 22,2 & 5 & 55,6 & 9 & 100 & $3 b$ \\
\hline 11 & $\begin{array}{l}\text { Pemberdayaan masyarakat } \\
\text { dalam PHBS }\end{array}$ & 2 & 22,2 & 4 & 44,4 & 1 & 11,1 & 2 & 22,2 & 9 & 100 & 2 \\
\hline 12 & Pengembangan UKBM & 1 & 11,1 & 6 & 66,7 & 0 & 0,0 & 2 & 22,2 & 9 & 100 & 2 \\
\hline 13 & Program gizi & 0 & 0,0 & 0 & 0,0 & 4 & 44,4 & 5 & 55,6 & 9 & 100 & $3 b$ \\
\hline
\end{tabular}

\section{Keterangan:}

1. Pusat penggerak pembangunan berwawasan kesehatan

2. Pusat pemberdayaan masyarakat

3. Pusat pelayanan kesehatan strata pertama : 3a. Pelayanan kesehatan perorangan; 3b. Pelayanan kesehatan masyarakat

instrumen PKP, program kesehatan wajib ini dinilai berdasarkan 30 jenis kegiatan. Walaupun 30 jenis kegiatan yang dinilai dalam PKP telah mengukur semua fungsi yang diatur dalam Kepmenkes Nomor 128/Menkes/SK/II/2004, persebaran penilaian setiap fungsi masih belum merata. Penelitian ini menunjukkan bahwa di antara 30 jenis kegiatan yang dinilai dalam PKP mayoritas kegiatan merupakan manifestasi dari fungsi puskesmas sebagai pelayanan kesehatan masyarakat. Fungsi puskesmas sebagai pusat pembangunan berwawasan kesehatan dan pemberdayaan masyarakat mendapat porsi penilaian yang sangat kecil. Tabel 1 menunjukkan mayoritas indikator penilaian lebih banyak menilai fungsi puskesmas sebagai pusat pelayanan dan tidak menilai dengan seimbang terhadap pelaksanaan fungsi yang lainnya. Walaupun tidak ada pembobotan pada setiap jenis kegiatan, tidak seimbangnya indikator penilaian yang tidak seimbang akan membuat puskesmas cenderung memilih fungsi yang lebih banyak dinilai.

Fungsi pelayanan kesehatan masyarakat juga masih menjadi jenis kegiatan yang paling banyak dinilai dalam komponen penilaian program pengembangan puskesmas. Fungsi pelayanan kesehatan perorangan dan pemberdayaan masyarakat hanya dinilai pada tidak lebih dari 3 jenis kegiatan saja. Mayoritas jenis kegiatan yang dinilai tetap pada program wajib puskesmas saja. Kondisi ini sama dengan fokus penilaian pada progam wajib puskesmas. Tabel 2 juga menunjukkan bahwa instrumen PKP pada komponen program pengembangan tidak mengukur sama sekali fungsi puskesmas sebagai pusat penggerak pembangunan berwawasan kesehatan.

Analisis yang dilakukan pada aspek pencapaian pelayanan kesehatan menyimpulkan bahwa mayoritas jenis kegiatan yang dinilai lebih banyak mengakomodasi penilaian terhadap fungsi puskesmas sebagai pelayanan kesehatan masyarakat. Beberapa komponen penilaian juga telah mengakomodasi kinerja fungsi puskesmas yang lain namun dengan proporsi yang tidak seimbang. Berkebalikan dengan fungsi pelayanan keseha- 
tan masyarakat yang banyak dinilai dalam kinerja program, fungsi ini ternyata tidak banyak dinilai dalam mutu pelayanan kesehatan yang ada di instrumen PKP.

Mutu pelayanan kesehatan yang ada dalam PKP justru lebih banyak menilai mutu pelayanan kesehatan perorangan. Hasil NGT juga menyimpulkan bahwa dari 11 komponen penilaian yang ada dalam indikator mutu pelayanan puskesmas tidak ada yang menilai tentang mutu pelayanan yang dilakukan puskesmas untuk mewujudkan fungsi pemberdayaan masyarakat. Sedangkan fungsi pusat penggerak pembangunan berwawasan kesehatan hanya diakomodasi dalam satu indikator saja.

Mutu pelayanan puskesmas yang diukur dalam PKP lebih banyak menilai mengenai fungsi pelayanan kesehatan perorangan. Pada Tabel 3 dijelaskan bahwa 7 dari 11 indikator yang digunakan dalam menilai mutu pelayanan kesehatan dominan menilai fungsi pelayanan kesehatan perorangan. Indikator mutu pelayanan yang digunakan hanya terkait pelayanan kesehatan reproduksi, tuberculosis, malaria, diare, kesehatan anak, serta terkait pengobatan umum. Masalah kesehatan yang digunakan tersebut dianggap sebagai masalah kesehatan utama yang dihadapi oleh semua puskesmas di Indonesia. Relevansi masalah kesehatan dengan kondisi masing-masing daerah belum terakomodasi dalam indiakator yang ada. Masalah spesifik daerah misalnya malaria cocok untuk daerah endemis, tetapi tidak cocok untuk wilayah perkotaan seperti Surabaya. Tabel 3 juga menunjukkan bahwa kesehatan reproduksi merupakan masalah kesehatan yang paling banyak dinilai dalam mengukur kualitas pelayanan puskesmas.

Instrumen PKP juga menilai kegiatan manajemen yang dilakukan oleh puskesmas. Semua fungsi puskesmas sudah diakomodasi dalam kegiatan manajemen puskesmas yang dinilai dalam enam jenis kegiatan manajemen puskesmas. Walaupun mayoritas semua fungsi sudah diakomodasi dalam jenis kegiatan yang dinilai pada aspek

Tabel 3. Akomodasi Fungsi Puskesmas dalam Komponen Penilaian Kinerja Puskesmas untuk Penilaian Mutu Pelayanan Puskesmas

\begin{tabular}{|c|c|c|c|c|c|c|c|c|c|c|c|c|}
\hline \multirow{3}{*}{ No. } & \multirow{3}{*}{ Jenis Kegiatan } & \multicolumn{8}{|c|}{ Fungsi } & \multirow{2}{*}{\multicolumn{2}{|c|}{ Total }} & \multirow{3}{*}{$\begin{array}{c}\text { Fungsi } \\
\text { yang } \\
\text { dominan }\end{array}$} \\
\hline & & \multicolumn{2}{|c|}{1} & \multicolumn{2}{|c|}{2} & \multicolumn{2}{|c|}{$\mathbf{3 a}$} & \multicolumn{2}{|c|}{$3 \mathbf{b}$} & & & \\
\hline & & $\mathbf{n}$ & $\%$ & $\mathbf{n}$ & $\%$ & $\mathbf{n}$ & $\%$ & $\mathbf{n}$ & $\%$ & $\mathbf{n}$ & $\%$ & \\
\hline 1 & $\begin{array}{l}\text { Drop out pelayanan ANC (K1- } \\
\text { K4) }\end{array}$ & 0 & 0,0 & 0 & 0,0 & 6 & 66,7 & 3 & 33,3 & 9 & 100 & $3 a$ \\
\hline 2 & $\begin{array}{l}\text { Persalinan oleh Tenaga } \\
\text { Kesehatan }\end{array}$ & 0 & 0,0 & 0 & 0,0 & 7 & 77,8 & 2 & 22,2 & 9 & 100 & $3 a$ \\
\hline 3 & $\begin{array}{l}\text { Penanganan Komplikasi } \\
\text { Obstetri / risiko tinggi }\end{array}$ & 0 & 0,0 & 0 & 0,0 & 7 & 77,8 & 2 & 22,2 & 9 & 100 & $3 a$ \\
\hline 4 & Error rate pemeriksaan BTA & 0 & 0,0 & 0 & 0,0 & 5 & 55,6 & 4 & 44,4 & 9 & 100 & $3 a$ \\
\hline 5 & $\begin{array}{l}\text { Error rate pemeriksaan darah } \\
\text { malaria }\end{array}$ & 0 & 0,0 & 0 & 0,0 & 4 & 44,4 & 5 & 55,6 & 9 & 100 & $3 b$ \\
\hline 6 & $\begin{array}{l}\text { Kepatuhan terhadap standar } \\
\text { ANC }\end{array}$ & 0 & 0,0 & 0 & 0,0 & 5 & 55,6 & 4 & 44,4 & 9 & 100 & $3 a$ \\
\hline 7 & $\begin{array}{l}\text { Kepatuhan terhadap standar } \\
\text { pemeriksaan TB Paru }\end{array}$ & 0 & 0,0 & 0 & 0,0 & 4 & 44,4 & 5 & 55,6 & 9 & 100 & $3 b$ \\
\hline 8 & $\begin{array}{l}\text { Tingkat kepuasan pasien } \\
\text { terhadap pelayanan Puskesmas }\end{array}$ & 0 & 0,0 & 0 & 0,0 & 5 & 55,6 & 4 & 44,4 & 9 & 100 & $3 a$ \\
\hline 9 & $\begin{array}{l}\text { Kematian kasus diare setelah } \\
\text { dirawat }>48 \text { jam (Nilai } \\
\text { Negatif) }\end{array}$ & 0 & 0,0 & 0 & 0,0 & 7 & 77,8 & 2 & 22,2 & 9 & 100 & $3 a$ \\
\hline 10 & Balita bawah garis merah & 0 & 0,0 & 0 & 0,0 & 4 & 44,4 & 5 & 55,6 & 9 & 100 & $3 b$ \\
\hline 11 & Drop Out DPT 1 - Campak & 2 & 22,2 & 0 & 0,0 & 3 & 33,3 & 4 & 44,4 & 9 & 100 & $3 b$ \\
\hline
\end{tabular}

\section{Keterangan:}

1. Pusat penggerak pembangunan berwawasan kesehatan

2. Pusat pemberdayaan masyarakat

3. Pusat pelayanan kesehatan strata pertama : 3a. Pelayanan kesehatan perorangan; 3b. Pelayanan kesehatan masyarakat 
manajemen puskesmas, fungsi pelayanan kesehatan perorangan masih mendominasi penilaian kinerja puskesmas pada fungsi pelayanan kesehatan perorangan. Khusus untuk kegiatan manajemen alat kesehatan dan obat, fungsi penggerak pembangunan berwawasan kesehatan dan pemberdayaan masyarakat belum terakomodasi sehingga instrumen PKP belum mampu menilai fungsi tersebut.

\section{PEMBAHASAN}

Fungsi puskesmas pada Permenkes Nomor 75 tahun 2014 menggantikan fungsi puskesmas yang sebelumnya diatur pada Kepmenkes Nomor 128/Menkes/SK/II/2004. Fungsi puskesmas pada Permenkes Nomor 75 Tahun 2014 pada dasarnya masih sama dengan fungsi puskesmas yang tercantum pada Kepmenkes Nomor 128/Menkes/ SK/II/2004. Pada Permenkes Nomor 75 Tahun 2014 hanya terjadi perubahan pada bertambahnya fungsi puskesmas sebagai wahana pendidikan tenaga kesehatan. Walaupun aturan mengenai fungsi puskesmas telah berubah, mekanisme penilaian kinerja puskesmas hingga saat ini tidak mengalami perubahan. Hal tersebut membawa konsekuensi adanya fungsi puskesmas yang tidak terakomodasi dalam instrumen Penilaian Kinerja Puskesmas (PKP).

Kinerja merepresentasikan sekumpulan tujuan yang akhirnya dapat dicapai oleh organisasi. ${ }^{4}$ Untuk dapat merepresentasikan kinerja organisasi maka indikator pengukuran yang digunakan untuk mengukur puskesmas seharusnya bertumpu pada tujuan organisasi dalam hal ini adalah fungsi puskesmas. Untuk dapat memperoleh gambaran kinerja organisasi yang mampu mengukur semua fungsi organisasi dapat dilakukan dengan memastikan bahwa dalam penyusunan indikator penilaian kinerja melibatkan semua stakeholder organisasi. ${ }^{5}$ Penyusunan indikator ini harusnya juga melibatkan tidak hanya Dinas Kesehatan, tetapi juga mengakomodasi stakeholder lain yang terkait dengan implementasi fungsi puskesmas.

Hasil penilaian kinerja pada setiap fungsi organisasi menunjukkan akuntabilitas organisasi tersebut dalam menjalankan fungsinya. ${ }^{6}$ Dalam mewujudkan akuntabilitas kinerja pada semua stakeholder, puskesmas harus mampu menunjukkan hasil penilaian kinerja secara terbuka dan menggunakan hasil penilaian kinerja tersebut un- tuk perbaikan kinerja. Ketidakseimbangan penggunaan indikator pada pengukuran kinerja akan membuat fungsi puskesmas yang sudah ditetapkan berpotensi untuk tidak dijalankan seluruhnya. Penilaian kinerja puskesmas yang tidak menggunakan indikator yang mengukur semua fungsi puskesmas secara seimbang tidak akan merepresentasikan hasil kerja puskesmas yang sebenarnya.

Penilaian kinerja sektor publik dapat menunjukkan kecenderungan pendanaan organisasi pada kriteria kinerja tertentu. ${ }^{3}$ Hasil PKP yang cenderung lebih menilai fungsi pelayanan kesehatan perorangan menunjukkan bahwa kemungkinan pendanaan di puskesmas juga masih diarahkan untuk kegiatan yang dominan tersebut. Pada era $\mathrm{JKN}$, hal ini dapat diminimalkan dengan memilah peruntukan dana kapitasi dan APBD. Penggunaan dana APBD untuk program kesehatan yang harusnya juga perlu diseimbangkan untuk dua fungsi lainnya, pusat penggerak pembangunan berwawasan kesehatan dan pemberdayaan masyarakat. Pelayanan kesehatan masyarakat tanpa adanya pemberdayaan yang diarahkan untuk pembangunan berwawasan kesehatan hanya hanya dapat menyelesaikan masalah secara sementara. Keberlangsungan program yang tidak bertumpu pada masyarakat tidak akan berkelanjutan., ${ }^{7,8}$

Puskesmas merupakan sebuah organisasi dengan lingkungan yang sangat dinamis. Dua perubahan besar yang mempengaruhi puskesmas adalah pemberlakukan fungsi baru dalam Permenkes Nomor 75 Tahun 2014 dan implementasi Jaminan Kesehatan Nasional perlu menjadi perhatian dalam pengelolaan puskesmas. Ukuran kinerja yang digunakan perlu disesuaikan dengan perubahan organisasi. ${ }^{9}$

Kebijakan pemerintah yang diperuntukkan mengatur organisasi publik harus mampu untuk mengukur hasil utama dari organisasi agar semua sistem yang terkait dapat berjalan dengan efisien. ${ }^{10}$ Permenkes Nomor 75 tahun 2014 diterbitkan setelah era Jaminan Kesehatan Nasional mulai dijalankan di Indonesia. Hal ini berdampak pada banyaknya pasal dalam Permenkes Nomor 75 tahun 2014 yang disesuaikan dengan kebutuhan dalam Jaminan Kesehatan Nasional. Misalnya, pada bagian pertama mengenai ketentuan umum yang mengatur peralatan kesehatan lebih banyak mengatur tentang berbagai peralatan kesehatan yang 
dibutuhkan untuk menyelesaikan 155 diagnosis penyakit yang harus selesai pada Fasilitas Kesehatan Tingkat Pertama (FKTP) BPJS Kesehatan. Kebutuhan alat yang dapat menunjang kegiatan promotif puskesmas belum diatur dalam Permenkes ini. Sebagai FKTP, aturan mengenai peralatan kesehatan tersebut memang sangat dibutuhkan untuk menunjang fungsi puskesmas sebagai penyelenggara Upaya Kesehatan Perorangan (UKP) tingkat pertama.

Walaupun penyusunan target pada saat perencanaan dapat meningkatkan motivasi dalam pencapaian, tetapi belum tentu dapat membuat semua perhatian dan upaya organisasi dapat terfokus pada pencapaian target. ${ }^{11}$ Untuk memaksimalkan target yang disusun, sistem pengukuran kinerja dan tujuan organisasi harus mampu memediasi hubungan antara kebijakan yang ada dengan kinerja yang ditunjukkan oleh organisasi. ${ }^{12}$ Oleh karena itu, fungsi puskesmas harus secara komprehensif tersusun dalam instrumen PKP agar dapat mengukur berbagai key performance indicator yang merupakan terjemahan dari fungsi puskesmas.

Tantangan utama organsasi dalam menggunakan instrumen penilaian kinerja adalah bagaimana mengintegrasikan berbagai ukuran kinerja dengan berbagai keputusan strategis maupun operasional organisasi. ${ }^{13}$ Ukuran kinerja organisasi harus dihasilkan dari sebuah analisis komprehensif mengenai berbagai aspek yang ada dalam organisasi. Ukuran kinerja harus mampu mengukur fungsi dari organisasi agar organisasi dapat tetap berkembang. ${ }^{14}$

Pada bagian kedua pada Permenkes Nomor 75 tahun 2014 yang mengatur upaya kesehatan telah diuraikan mengenai fungsi penyelenggaraan UKM tingkat pertama. Sayangnya penjelasan mengenai pemberdayaan masyarakat serta kerjasama lintas sektor dalam pelaksanaan berbagai upaya puskesmas belum nampak jelas dalam Permenkes ini. Padahal pada Kepmenkes Nomor 128/Menkes/SK/II/2004, fungsi pemberdayaan masyarakat yang memanfaatkan lintas sektor telah dijelaskan melalui adanya Badan Penyantun Puskesmas (BPP). Dalam Permenkes Nomor 75 tahun 2014 tidak disebutkan mengenai eksistensi BPP. Permenkes Nomor 75 tahun 2014 juga mengatur mengenai akreditasi puskesmas. Akreditasi puskesmas merupakan ketentuan baru yang wajib dijalankan oleh puskesmas. Akreditasi puskesmas muncul untuk menjawab tuntutan Permenkes Nomor 71 tahun 2013 tentang Pelayanan Kesehatan pada Jaminan Kesehatan Nasional bahwa setiap FKTP yang bekerjasama dengan BPJS Kesehatan harus terakreditasi.

Penjabaran mengenai yang dimaksud dengan fungsi wahana pendidikan bagi tenaga kesehatan dibutuhkan untuk menentukan jenis kegiatan yang selanjutnya menjadi tolok ukur kinerja puskesmas pada implementasi fungsi tersebut. Instrumen PKP seharusnya mengakomodasi jenis kegiatan tersebut sehingga puskesmas tidak terlewat mengerjakan yang seharusnya menjadi fungsinya. Hal ini juga mengingat bahwa pertambahan fungsi tersebut tentunya akan membawa konsekuensi bagi bertambahnya beban kerja puskesmas.

Hasil penelitian menunjukkan bahwa semua fungsi puskesmas dalam Kepmenkes Nomor 128/ Menkes/SK/II/2004 telah terakomodasi dalam PKP, tetapi dalam proporsi yang belum seimbang. Komponen penilaian dalam PKP ini masih banyak menyoroti kinerja puskesmas dalam aktivitas pelayanan saja. Fungsi puskesmas sebagai penggerak pembangunan bewawasan kesehatan dan pemberdayaan masyarakat belum banyak diakomodasi. Perlu diingat bahwa sebuah sistem pengukuran kinerja pada organisasi sektor publik harus berdasarkan objektif yang disusun sesuai rencana strategis. Kemampuan instrumen penilaian kinerja mengakomodasi objektif dari organisasi akan membantu organisasi untuk dapat menggambarkan dengan jelas kondisi organisasi saat ini dan menentukan tindakan korektif untuk masa depan organisasi.

Komponen penilaian kinerja puskesmas yang lebih banyak mengukur kinerja aktivitas pada fungsi pelayanan kesehatan akan menimbulkan kemungkinan puskesmas hanya akan berfokus pada fungsi yang banyak dinilai saja. Fungsi lain yang tidak tertampung dalam komponen Penilaian Kinerja Puskesmas kemungkinan akan terpinggirkan. Pada penilaian kinerja seperti PKP yang cenderung menggunakan pendekatan goal orient$e d$, ukuran kinerja harus ditentukan sesuai dengan tujuan yang ingin dicapai oleh organisasi. Tujuan organisasi ini harus mencerminkan fungsi dari organisasi. ${ }^{15}$ Dalam penilaian kinerja yang berbasis goal-oriented model, organisasi diasumsikan 
memiliki tujuan khusus yang terukur, realistis, operasional, dan relevan dengan fungsi dari organisasi. ${ }^{16}$

Variabel yang ada dalam PKP mewakili fungsi, azas, dan upaya pelayanan puskesmas beserta jaringannya. Mutu pelayanan merupakan salah satu komponen penilaian yang dijadikan objek penilaian dalam PKP. Setiap fungsi dari puskesmas memiliki aktivitas pelayanan yang spesifik. Penilaian kinerja yang baik seharusnya mampu memotret semua ukuran aktivitas pelayanan yang diberikan oleh organisasi. Kurangnya kriteria yang mengukur setiap fungsi dari organisasi akan membuat anggota organisasi mengalami demotivasi untuk berkinerja baik pada fungsi organisasi yang tidak diukur. ${ }^{17}$

Selama ini, PKP diakui belum mampu mengakomadasi semua kegiatan pelayanan. Hal ini sesuai dengan yang tercantum dalam Pedoman Penilaian Kinerja puskesmas di Jawa Timur yang dikeluarkan tahun 2012. Pada pedoman tersebut dijelaskan bahwa memang belum semua kegiatan pelayanan yang dilaksanakan di puskesmas dapat dinilai tingkat mutunya, baik dalam aspek input, proses, output maupun outcome-nya karena indikator dan mekanisme untuk penilaiannya belum ditentukan. Sehingga secara keseluruhan tidak akan diukur dalam penilaian kinerja, akan tetapi dipilih beberapa indikator yang sudah ada standar penilaiannya. Belum terakomodasinya semua fungsi dan belum mampunya indikator kinerja dalam PKP harus segera ditindaklanjuti. Hasil penelitian menunjukkan adanya ketimpangan pelaksanaan fungsi puskesmas yang dinilai pada komponen penilaian aktivitas manajemen puskesmas dalam PKP. Pada komponen ini, penilaian kinerja puskesmas lebih banyak menyoroti fungsi pelayanan kesehatan pelayanan perorangan. Kondisi ini menjadi penguat bahwa beban puskesmas terkait administratif pelayanan kesehatan pengobatan memang tinggi. Kegiatan manajemen paling banyak menyita waktu sehingga waktu puskesmas banyak dihabiskan untuk kegiatan yang sifatnya administratif dari pelayanan kesehatan pelayanan perorangan.

Agar dapat membantu puskesmas mengimplementasikan fungsinya secara seimbang, instrumen Penilaian Kinerja Puskesmas harus dirancang untuk dapat mengukur setiap aktivitas dalam seti- ap fungsi. Tujuan dari sistem pengukuran kinerja pada organisasi publik adalah untuk dapat menilai secara kuantitatif tingkat pencapaian tujuan dan fungsi organisasi. Dengan menganalisis kinerja puskesmas sesuai fungsinya maka Dinas Kesehatan akan lebih mudah dalam mengalokasikan anggaran untuk mendukung implementasi fungsi puskesmas tanpa hanya terfokus pada satu fungsi tertentu saja. Penilaian kinerja organisasi yang baik adalah instrumen yang mampu memotret berbagai kontekstual organisasi termasuk implementasi fungsi organisasi yang akan menentukan keberlangsungan organisasi. Dalam sebuah organisasi non profit, fungsi organisasi yang biasanya tertuang dalam pernyataan misi menjadi dasar penentuan tujuan organisasi yang tercermin dalam aktivitas organisasi tersebut.

Fungsi puskesmas telah diatur oleh peraturan terbaru yakni Permenkes Nomor 75 tahun 2014, maka seharusnya instrumen PKP yang digunakan juga disesuaikan dengan tambahan fungsi puskesmas yang ada dalam peraturan tersebut. Melakukan kajian dan meng-update instrumen penilaian kinerja harus didasarkan juga pada lingkungan eksternal organisasi termasuk perubahan kebijakan pada supra sistem organisasi tersebut.

\section{KESIMPULAN DAN SARAN}

Berdasarkan analisis terhadap ketiga komponen penilaian kinerja puskesmas yang ada dalam PKP, nampak belum adanya akomodasi yang seimbang untuk setiap fungsi puskesmas. Tidak semua fungsi diatur dalam komponen penilaian PKP. Sinkronisasi dari setiap komponen penilaian untuk setiap fungsi juga belum nampak. Misalnya, pada fungsi pelayanan kesehatan masyarakat yang paling dominan dalam komponen program puskesmas ternyata belum banyak diatur mengenai indikator mutu pelayanan serta kegiatan manajemennya dalam PKP. Dinas Kesehatan Provinsi perlu melakukan revisi instrumen Penilaian Kinerja Puskesmas sesuai dengan apa saja aktivitas yang seharusnya dilakukan untuk menunjang implementasi fungsi puskesmas. Fungsi puskesmas yang dinilai juga harus memperhatikan perubahan aturan terbaru yang mengatur fungsi puskesmas. Dengan melakukan revisi terhadap instrumen PKP maka Dinas Kesehatan dan puskesmas akan dapat memantau beban aktivitas pada setiap fung- 
si sehingga dapat menyeimbangkan aktivitas yang dilakukan oleh puskesmas.

\section{UCAPAN TERIMA KASIH}

Penulis mengucapkan terima kasih kepada para kepala Puskesmas Kota Surabaya yang telah bersedia ikut serta dalam penelitian ini. Kolaborasi dan kerjasama Dinas Kesehatan Kota Surabaya dalam analisis peraturan yang dibahas dalam penelitian ini juga sangat diapresiasi oleh penulis.

\section{DAFTAR PUSTAKA}

1. Bappenas. Health Sector Review Kumpulan Policy Brief Health Sector Review Kumpulan Policy Brief. 2013. 1-84 p.

2. Supriyantoro, Hendarwan H, Savithri Y. Studi Kasus Implementasi Paket Manfaat Jaminan Kesehatan Daerah (Jamkesda). Bul Penelit Sist Kesehat. 2014;17(14):327-36.

3. Doderqlhqo Q. The Aspects of Performance Measurement in Public Sector Organization. 2015;213:314-20.

4. Kouzmin A, Lo E, Korac-kakabadse N. Benchmarking and Performance Measurement in Public Sectors. 1999;12(2):121-44.

5. Agostino D, Gestionale I, Milano P, Gestionale I, Milano P, Molin MD, et al. Developing a Performance Measurement System for Public Research Centres. Int J Bus Appl Manag. 2012;7(1):43-55.

6. Cavalluzzo KS, Ittner CD. Implementing Performance Measurement Innovations: Evidence From Government. 2003;29(2004):24367.

7. Uche OA, Uzoma O, Uche IB. Sustainable Community Development: An Insight Into the Niger Delta Development Commission (NDDC) Community Development Projects in Abia State. Glob Adv Res J Manag Bus
Stud [Internet]. 2014;3(12):2315-5086.

8. Schell SF, Luke D a, Schooley MW, Elliott MB, Herbers SH, Mueller NB, et al. Public Health Program Capacity for Sustainability: A New Framework. Implement Sci [Internet]. 2013;8(1):15.

9. Lin J, Lee P. Performance Management in Public Organizations: A Complexity Perspective. Int Public Manag Rev. 2011;12(2):81-96.

10. Curristine T, Lonti Z, Joumard I. Improving Public Sector Efficiency: Challenges and Opportunities. J Budg. 2007;7(1):1-42.

11. Eden R, Hyndman N. Performance Measurement in the UK Public Sector: Poisoned Chalice or Holy Grail ? J Public Sect Manag. 2016;29(1):9-15.

12. Har M, Mohamad S, Ismail S. The Effect of Regulation and Goal Orientation on Performance Measurement Utilisation: Evidence from Indonesian Local Governments. 2014;7(1):81-106.

13. Markic D. A Review on the Use of Performance Indicators in the Public Sector. Technol Educ Manag J. 2014;3(1):22-8.

14. Muchiri P, Pintelon L, Gelders L, Martin H. Development of Maintenance Function Performance Measurement Framework and Indicators. Intern J Prod Econ [Internet]. Elsevier; 2010;1-8. Available from: http://dx.doi. org/10.1016/j.ijpe.2010.04.039

15. Poister TH. Measuring Performance in Public and Nonprofit Organizations.

16. Ruzita J, Azhar R, Hasan HABU. Performance Measurement Practice of Public Sectors in Evolution of Performance Measurement. J Glob Strateg Manag. 2008;6(1):42-56.

17. Velimirovi D, Velimirovi M, Stankovi R, New I, Kpi I. Role and Importance of Key Performance Indicators Measurement. Serbian J Manag. 2011;6(1):63-72. 